Louisiana State University

LSU Digital Commons

Faculty Publications

Department of Oceanography \& Coastal

Sciences

2004

Inorganic Nitrogen Transformations at High Loading Rates in an Oligohaline Estuary

R. Eugene Turner

Q. Dortch

Nancy N. Rabalais

Follow this and additional works at: https://digitalcommons.Isu.edu/oceanography_coastal_pubs

Digitart of the Oceanography Commons

Commons

Network

Logo 


\title{
Inorganic nitrogen transformations at high loading rates in an oligohaline estuary
}

\author{
R.E. TURNER ${ }^{1, *}$, Q. DORTCH ${ }^{2}$ and N.N. RABALAIS ${ }^{2}$ \\ ${ }^{I}$ Department of Oceanography and Coastal Sciences, Coastal Ecology Institute, Louisiana State \\ University, Baton Rouge, Louisiana, 70803, USA; ${ }^{2}$ Louisiana Universities Marine Consortium, 8124 \\ Highway 56, Chauvin, Louisiana 70344, USA; *Author for correspondence
}

Received 19 September 2001; accepted in revised form 4 June 2003

Key words: Estuary, Nitrogen, Nutrient cycling, Phosphorus, Suspended sediments

\begin{abstract}
A well-defined nitrogen retention and turnover budget was estimated for a shallow oligohaline lake (Lake Pontchartrain, Louisiana, USA). In 1997 a month-long diversion of the Mississippi River filled the Lake with highly concentrated river water $(80 \mu \mathrm{M}$ nitrate) and lowered the salinity to $0 \mathrm{psu}$ within 2 weeks. After the spillway was closed the Lake mixed with estuarine tidal waters and came to equilibrium over 4 months with the riverine, atmospheric and offshore water nitrogen sources. A flushing rate of $1.78 \% \mathrm{~d}^{-1}$ was estimated by analyzing a plot of $\ln$ salinity versus time for the first 120 days after the diversion ceased. This flushing rate was similar to the loss rate for total nitrogen $\left(1.75 \% \mathrm{~d}^{-1}\right)$, implying no significant net nitrogen losses or gains were occurring inside the Lake. The percent loss of dissolved inorganic nitrogen was higher than that for TN $\left(4.11 \% \mathrm{~d}^{-1}\right)$, whereas the loss of organic nitrogen was lower $\left(0.94 \% \mathrm{~d}^{-1}\right)$, which suggests a net transfer from inorganic to organic nitrogen. These changes occurred steadily as chlorophyll a concentration ranged from 5 to $200 \mu \mathrm{g} 1^{-1}$. The results demonstrate the potential significance of the organic nitrogen and interconversion of nitrogen forms when calculating estuarine nitrogen retention budgets and the necessity of measuring all nitrogen forms when performing mass balance estimates. The significance of denitrification in nitrogen removal is minimal at the high loading rates observed during this study. An implication to estuarine water quality management is that the relationships between nitrogen loading and retention are not linear and are controlled by factors other than water residence time.
\end{abstract}

\section{Introduction}

Building a field-based nutrient input-output budget for estuaries poses logistical, financial and research issues that are additive and often more complex than found in limnetic environments of comparable size. Estuarine scientists attempting to estimate nitrogen retention rates face the two-headed problem of simultaneously determining the flushing rate and building a total nitrogen budget. Estimates of nitrogen retention in coastal waters are often (and understandably) based on incomplete independent measurements of nitrification, denitrification and sedimentation, or modeling studies, or a combination of these approaches (e.g., Nielsen et al. 1995; Trimmer et al. 1998). Nevertheless, these efforts suggest that the retention of nitrogen flowing into estuaries and the cycling rates within estuaries are directly related to the in situ nutrient concentration and indirectly related to estuarine flushing (Nielsen et al. 1995; Nixon et al. 1996).

The problem of knowing the estuarine flushing rate might be overcome by physical oceanographers equipped with models, current meters, and various tracers. Coupling 


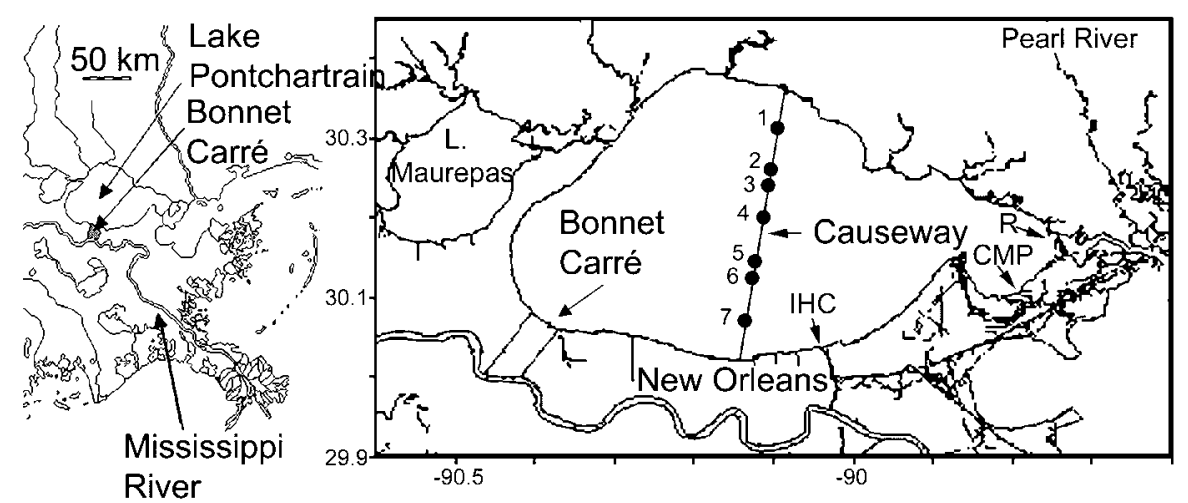

Figure 1. Location map for Lake Pontchartrain, local major tributaries, the New Orleans metropolitan area, the seven sampling stations on the Causeway, and the Bonnet Carré Spillway (shaded). $\mathrm{R}=$ Rigolets $; \mathrm{CMP}=$ Chef Menteur Pass; $\mathrm{IHC}=$ Inner Harbor Navigation Channel.

those measurements to nutrient cycling rates is more difficult. We were able to do both and build a nitrogen retention model for Lake Pontchartrain, a shallow estuarine water body near New Orleans, LA, USA, by using data collected after the diversion of Mississippi River water through the Bonnet Carré spillway in spring 1997. The diversion volume was so great that it changed the salinity of the normally brackish lake to 0 psu within weeks. We documented the subsequent salinization of the Lake to determine an estuarine flushing rate, and the dilution of the highly enriched water to measure the net transfers between various dissolved and particulate nitrogen forms. In this way we estimated the net retention of all forms of nitrogen in this estuary and their transformation to other forms.

\section{The Lake Pontchartrain environment}

Lake Pontchartrain (Figure 1) is a shallow (3.7 m average depth) lake with a surface area of about $1630 \mathrm{~km}^{2}$, volume of $6.0 \mathrm{~km}^{3}$, and a salinity that is generally less than 5 psu. Lake circulation is wind driven, the water column is usually well-mixed, and the $11 \mathrm{~cm}$ tides are primarily diurnal (Chuang and Swenson 1981). The flushing time for Lake Pontchartrain is about 60 days (Swenson 1980a). It has a narrow connection to the sea through the Rigolets and Chef Menteur Pass on the eastern end. The fresh water balance in Lake Pontchartrain is controlled largely by the watershed riverflow into the lake, but also from the fresh water entering through the tidal channels including that from the Pearl River. Water budget calculations by Swenson $(1980 \mathrm{a}, \mathrm{b})$ indicate that the annual riverflow into Lake Pontchartrain is about $300 \mathrm{~m}^{3} \mathrm{~s}^{-1}$, which equals about $0.44 \% \mathrm{~d}^{-1}$ of the water volume of the lake. The tidal flows into (and out of) the Lake are about $7500 \mathrm{~m}^{3} \mathrm{~s}^{-1}$ with $60 \%$ flowing through the Rigolets, 33\% flowing through the Chef Menteur Pass and the remainder $(7 \%)$ flowing through the Inner Harbor Navigation Channel (in New 
Orleans). The combined annual freshwater inflows amount to about 5\% of the volume of the tidal prism entering through tidal passes (Swenson 1981). Canals from the city of New Orleans empty into Lake Pontchartrain on its southern shore carrying storm drainage runoff and leakage from sewers.

The Bonnet Carré Spillway, a floodwater spillway protecting New Orleans, is located on the southwestern end of Lake Pontchartrain. This Spillway diverted Mississippi River water into Lake Pontchartrain in 1937, 1950, 1973, 1975, 1979, 1983 and 1997. Some leakage occurs seasonally from the Mississippi River into Lake Pontchartrain when river heights rise sufficiently to top the Bonnet Carré levee (when water levels are greater than $12.5 \mathrm{ft}$ NGVD). This leakage and apparent vandalism in 1995 resulted in a peak diversion flow of $14,000 \mathrm{cfs}\left(406 \mathrm{~m}^{3} \mathrm{~s}^{-1}\right)$. The 1997 spillway openinzg lasted from March 17 to April 18 with a peak flow of $250,000 \mathrm{cfs}\left(6793 \mathrm{~m}^{3} \mathrm{~s}^{-1}\right)$ and a cumulative flow of $11.8 \mathrm{~km}^{3}$, equivalent to about twice the Lake's volume in 1 month.

\section{Materials and methods}

Water samples from Lake Pontchartrain were collected by bucket at seven stations along the causeway oriented roughly north to south (Figure 1). These samples were frozen for nutrients or processed for phytoplankton pigments within $6 \mathrm{hr}$. Sub-samples were analyzed for nitrate + nitrite, nitrate, ammonium, ortho-phosphate (DIP), silicate, Total Kjeldahl Nitrogen (TKN), and Total Phosphorus (TP) with a Technicon AutoAnalyzer II using US EPA approved methods described in APHA (1992). Organic nitrogen was calculated as TKN - ammonium. Salinity was calculated from conductivity measured upon return to the laboratory with a standard laboratory conductivity meter or chloridimeter (titrated sample using silver wire). Suspended sediment concentrations were determined by filtering a known volume of water through a combusted $\left(550^{\circ} \mathrm{C}\right.$ ) and pre-weighed glass fiber filter (Whatman Type GF/F or equivalent). The filters were dried (at $60^{\circ} \mathrm{C}$ ) then re-weighed to determine total suspended load in $\mathrm{mg} \mathrm{l}^{-1}$. The filters were then combusted at $550{ }^{\circ} \mathrm{C}$, cooled, then reweighed to determine percent organic content (APHA 1992). Plankton were concentrated by filtering water samples at a low vacuum through a glass fiber filter (GFF). The phytoplankton pigments are extracted using a solution of $60 \%$ Acetone and $40 \%$ dimethyl sulfoxide (DMSO). The samples were stored for 2-24h (maximum) to extract the chlorophyll a ( $\mathrm{Chl} \mathrm{a),} \mathrm{the} \mathrm{sample} \mathrm{centrifuged} \mathrm{to} \mathrm{clarify} \mathrm{the} \mathrm{solution,} \mathrm{and} \mathrm{the}$ fluorescence measured before and after acidification with $0.1 \mathrm{~N} \mathrm{HCl}$. The fluorescence readings were then used to calculate the concentration (in $\mu \mathrm{gl}^{-1}$ ) of $\mathrm{Chl}$ a and pheophytin a. This procedure is a modification of EPA method 445.0 (Arar and Collins 1992 ) in which DMSO is used in lieu of grinding in $90 \%$ acetone to extract pigments.

Water samples from the Mississippi River at the spillway entrance were collected biweekly during the spillway opening. The uptake of material across the spillway before it entered the Lake is insignificant at these loading rates (Turner et al. 2003b). Riverflow volumes into the spillway were obtained from the US Army Corps of Engineers (US ACOE), New Orleans District office. 
A nitrogen budget for Lake Pontchartrain is from Turner et al. (2003a) that included nitrogen fixation rates in the Lake, stream discharges and nitrogen concentrations, atmospheric loading, urban runoff and leakage through the Bonnet Carré spillway when it is not open. An estimate of nitrogen from the spillway opening is from US ACOE discharge measurements and the nitrogen concentration measured at the spillway entrance.

The rates of change were estimated from the turnover rates described below, which are for the average of the seven stations in the middle of the Lake (on the Causeway). The changes in various constituents were compared to changes in salinity for the period when the primary source of water the Lake was the diverted water which was being diluted by water entering at the eastern end of the Lake. This period was for when the slope of a plot of ln (salinity) versus time was linear. Salinity was assumed to be a conservative tracer of flushing rate. Similar ln transformations for the other measured constituents were made and the apparent loss rates determined in the same fashion as for the conservative constituent salinity. These loss rates are the net result of significant transformations, storages or additions of constituents occurring within the Lake, and also are dependent on the end-member concentration (the diluent). The sign of the slope is positive in the case of salinity, because Lake water is mixing with water of a higher salinity value. The opposite is true for all other constituents, and the sign of the slope is therefore expected to be negative.

\section{Results}

\section{Salinity changes}

The average salinity at the seven causeway stations is shown in Figure 2 in two ways. One data presentation is the average values ( \pm 1 Standard Deviation) versus time (Julian Day). When the spillway was open in March 1997, the salinity had been about 4 psu or higher for the previous 12 months. Immediately afterwards, the average salinity dropped to less than 0.2 psu until it reached its previous level 4-5 months after the spillway closed. The second data presentation is a plot of ln salinity (Figure 2). It clearly shows a linear period of recovery for about 120 days after the diversion stopped. The salinity data from this period were analyzed to determine the slope of the $\ln$ transformed data over time, and are shown in Figure 3. The regression line has an $R^{2}$ of 0.98 and a slope of 0.0178 , thus indicating a daily flushing rate of $1.78 \% \mathrm{~d}^{-1}$. This number compares well with the average freshwater flushing rate of $2 \% \mathrm{~d}^{-1}$ estimated by Swenson (1980a). It would take 128 days to reduce a conservative tracer to $10 \%$ of its initial concentration at a loss rate of $1.78 \% \mathrm{~d}^{-1}$.

\section{$N$ loading}

The total amount of water entering Lake Pontchartrain during the 1997 diversion was about $11.8 \mathrm{~km}^{3}$, which is equivalent to twice the volume of the Lake. The 


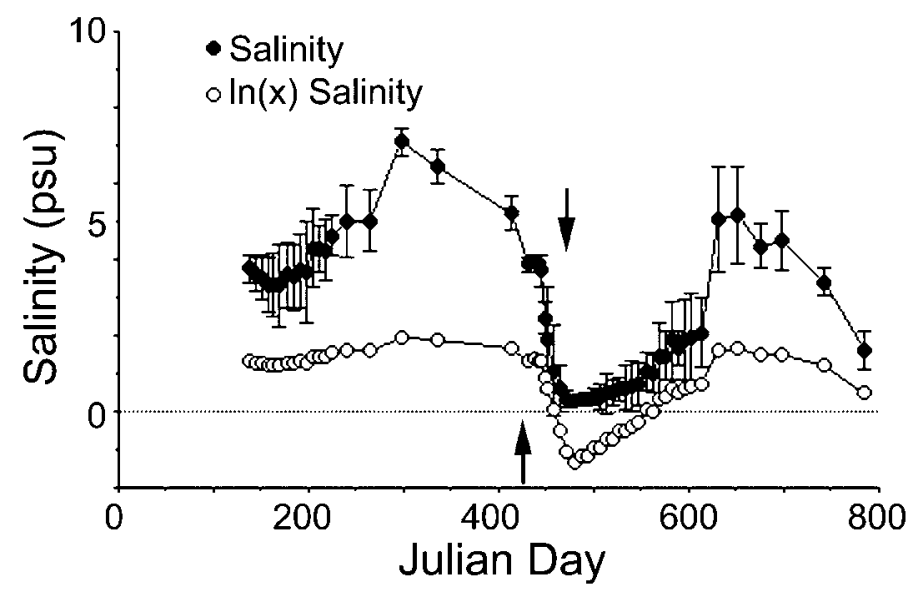

Figure 2. Average salinity at the seven causeway stations ( \pm 1 Standard Deviation). Julian Day 1 is 1 January 1996. The diversion started 17 March $1997(\Uparrow)$ and ended 18 April $1997(\Downarrow)$.

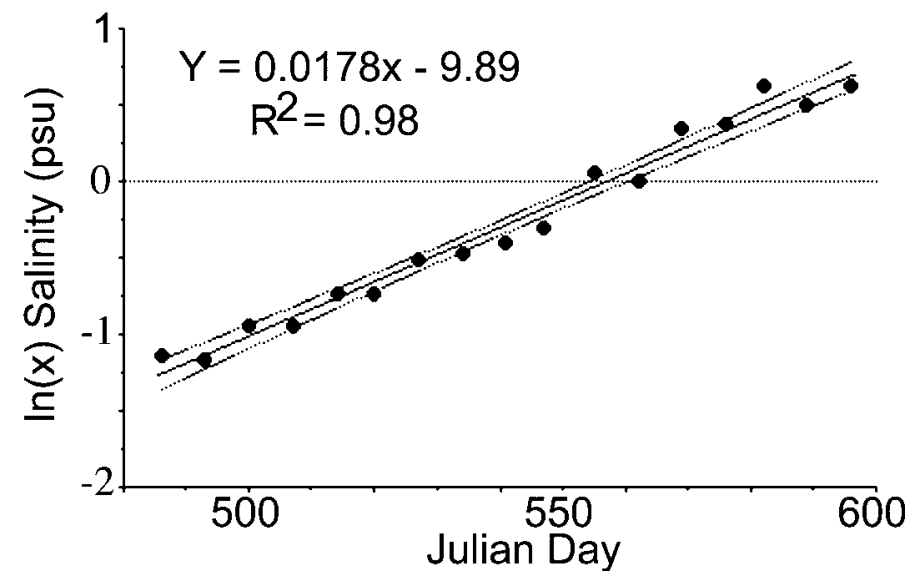

Figure 3. The relationship between $\ln$ (salinity) at the seven causeway stations and Julian Day for the 120-day period after the spillway diversion stopped. Julian Day 1 is 1 January 1996.

nitrogen concentration in the Mississippi River is dominated by nitrate (Turner and Rabalais 1991, Turner et al. 2003b), whose concentration during the spring 1997 was around $80 \mu \mathrm{M}$. A total nitrogen load of $16.2 \times 10^{6} \mathrm{~kg} \mathrm{~N}$ was delivered in 1 month, which is equal to 20 times that delivered in 1 year by watershed sources into a water body with an average nitrate concentration of less than $3 \mu \mathrm{M}$ in nondiversion years. The average peak nitrogen loading during the diversion event was about three times the annual average (Turner et al. 2003a). The total loading from the spillway opening was about $100 \mathrm{~kg} \mathrm{Nha}^{-1}\left(10 \mathrm{gN} \mathrm{m}^{-2}\right)$ or $992 \mu \mathrm{MN} \mathrm{m}^{-2} \mathrm{~h}^{-1}$ over the 30 days of the diversion opening. These loading rates are higher than any 
Table 1. Estimated rates of change during Julian Days 480-600 (beginning 1 January 1996) for water samples taken along the Lake Pontchartrain Causeway. (Abbreviations: S.E. $= \pm 1$ standard error; Adj. $R^{2}=$ coefficient of determination; $N=$ number of samples; NA = not applicable; NS = not significant at the $95 \%$ confidence level. Days 527 and 534 are excluded from the analysis (but not for the salinity data) because of the potential confounding effects of a massive algal bloom then.

\begin{tabular}{lllll}
\hline Parameter & $\% \mathrm{~d}^{-1}$ & S.E. & Adj. $R^{2}$ & $N$ \\
\hline Salinity & 1.78 & 0.07 & $0.98^{* *}$ & 17 \\
Nitrite & -1.64 & 0.30 & $0.68^{* *}$ & 15 \\
Nitrate & -5.12 & 0.4 & $0.91^{* *}$ & 15 \\
Nitrate + Nitrite & -4.9 & 0.4 & $0.91^{* *}$ & 15 \\
DIN (dissolved inorganic nitrogen) & -3.85 & 0.30 & $0.92^{* *}$ & 15 \\
TKN (total Kjeldahl nitrogen) & -0.93 & 0.17 & $0.66^{*}$ & 15 \\
Organic N & -0.94 & 0.18 & $0.64^{*}$ & 15 \\
TN (total nitrogen) & -1.75 & 0.15 & $0.91^{* *}$ & 15 \\
DIP (dissolved inorganic ortho-phosphate) & $\mathrm{NS}$ & - & - & 15 \\
TP (total phosphorus) & $\mathrm{NS}$ & - & - & 15 \\
Si (silicate) & -0.80 & 0.11 & $0.79^{* *}$ & 15 \\
TN/TP & -1.82 & 0.52 & $0.44^{* *}$ & 15 \\
DIN/DIP & -2.69 & 0.57 & $0.60^{* *}$ & 15 \\
Si/DIN & 3.34 & 0.28 & $0.91^{* *}$ & 15 \\
\hline
\end{tabular}

${ }^{*} p<0.01$.

$* * p<0.05$ and $>0.01$.

of the equivalent estuarine values listed in Seitzinger (1988). The nitrogen loading from New Orleans and vicinity urban runoff mostly goes into the Mississippi River, and the amount delivered from south shore canals was estimated to be less than that delivered by all riverine sources. Atmospheric $\mathrm{N}$ sources measured at three stations in the region was estimated to be $5 \mathrm{~kg} \mathrm{Nha}^{-1}$ year $^{-1}$ for the surface of the Lake. The diversion, therefore, delivered in the 30 days it was open the equivalent of many years of nitrogen from all other sources. The diversion through the spillway and into the Lake was clearly the overwhelming nitrogen and freshwater source to the Lake during spring 1997.

\section{$N$ transformations}

The following sections address the question of how much of the nitrogen in Lake Pontchartrain after the spillway operation was subsequently lost through biological transformations, sedimentation, or dilution.

The slopes, standard error, and $R^{2}$ values for the rate of change for all constituents are listed in Table 1 . These varied between -0.80 and $-5.12 \% \mathrm{~d}^{-1}$, indicating that some constituents had a significant net storage and/or loss within the Lake because they were so different from the inverse of the salinity slope (1.78). If there were significant nutrient concentrations in the diluent then the loss rate of TN would be lower than for - salinity (the slopes would be less negative). But the loss terms for - salinity and TN are the same (they would be different if there were local 


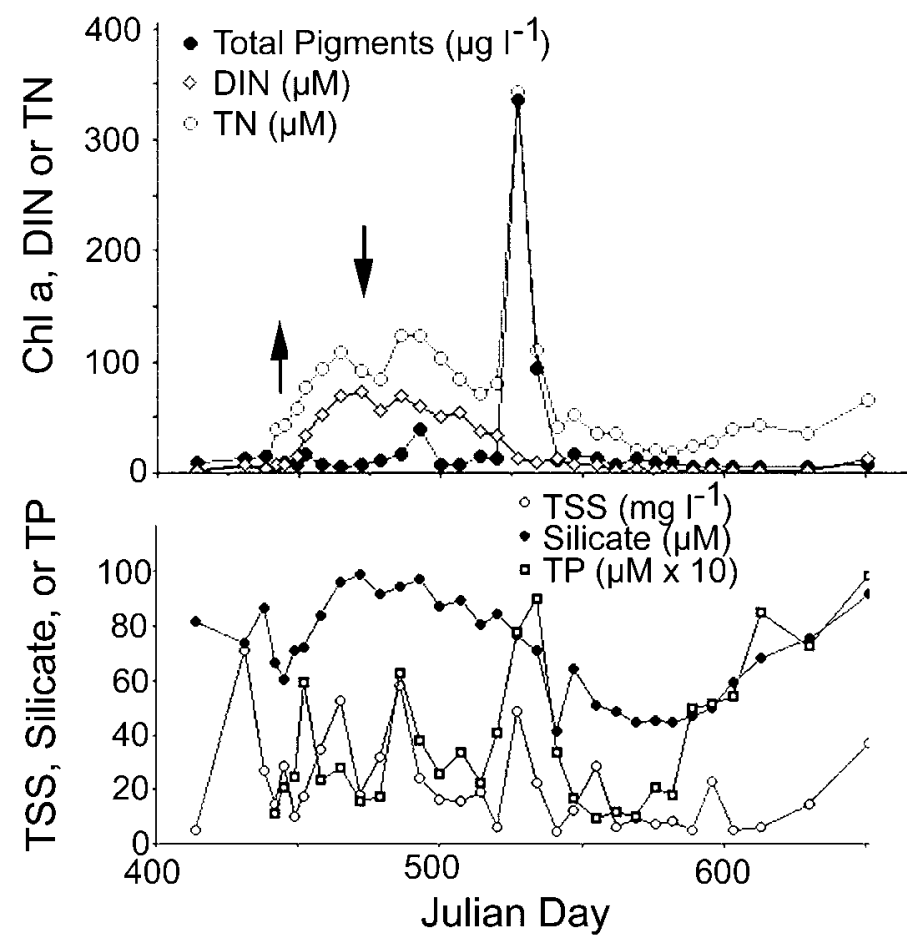

Figure 4. Average values for the seven causeway stations. Upper panel: total nitrogen $(\mu \mathrm{M})$, dissolved inorganic nitrogen $(\mu \mathrm{M})$ and phytoplankton pigments $\left(\mu \mathrm{g} 1^{-1}\right)$. Lower panel: total suspended sediments, silicate and total phosphorus (TP; $\mu \mathrm{M} \times 10$ ). Julian Day 1 is 1 January 1996. The diversion started 17 March 1997 (Day 442) and ended 18 April 1997 (Day 474), signified by arrows.

additional sources of either TN or salt), and there was no significant nitrogen fixation in the Lake (Turner et al. 2003a).

The effect of local rivers on the Lake's water chemistry would only resume after many months for several reasons. First, the local river discharge is low $\left(300 \mathrm{~m}^{3} \mathrm{~s}^{-1}\right)$ relative to the volume of the Lake (annual average $=0.44 \% \mathrm{~d}^{-1}$ ) and the daily turnover in the Lake is $1.78 \% \mathrm{~d}^{-1}$. The diversion was twice the Lake's volume and so it spilled into the coastal region outside of the Lake, which means that the essentially nutrient depleted ocean becomes the diluent. Second, the nitrogen concentration in the local rivers is much lower than in the diverted water. The concentration of nitrate in the Mississippi River, for example, is $>80 \mu \mathrm{M}$ compared to the normal $<3 \mu \mathrm{M}$ in the Lake and $15 \mu \mathrm{M}$ in the local rivers. In other words, the effect of the local rivers would be small relative to what is in the Lake for the first 2 months after the diversion is closed. If either the diluent concentration were significant, then the $R^{2}$ for the slope of the plot of $\ln$ (constituent) versus time would be statistically insignificant or less than 0.9 .

The slopes for various nitrogen forms and a plot of the concentrations versus time demonstrate interesting transformations after the spillway closed. The 


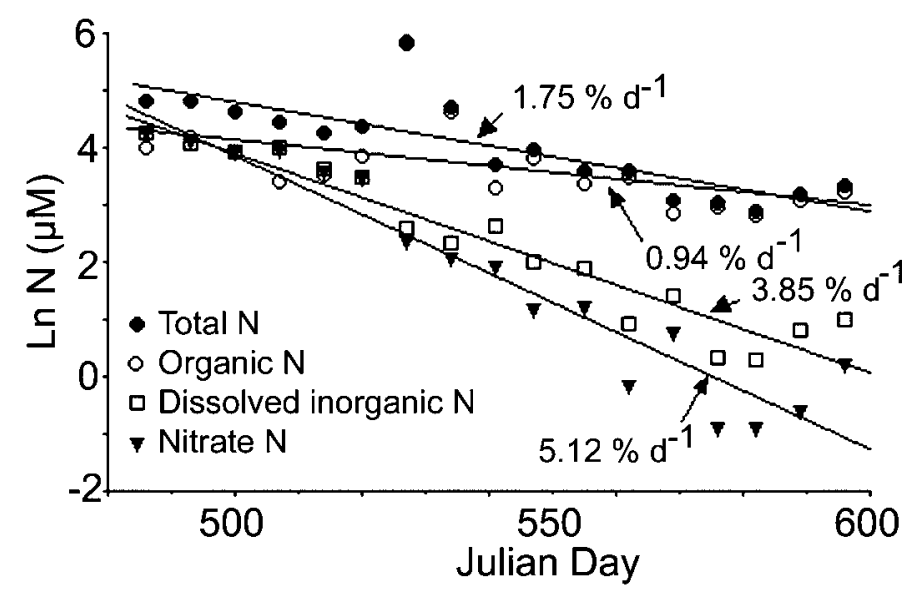

Figure 5. The relationship between the $\ln$ of nitrate, dissolved inorganic nitrogen, organic nitrogen and total nitrogen at the seven causeway stations and Julian Day for the 120 day period after the spillway diversion stopped (Julian Day 474). Samples for Days 527 and 534 were excluded for reasons discussed in the text. The slope of each regression is shown. Julian Day 1 is 1 January 1996.

dominant nitrogen form was initially DIN, but then became organic nitrogen at the end of the summer as TSS and Si declined (Figure 4). There was a dramatic phytoplankton bloom during June, which had an average Chl a value of more than $334 \mu \mathrm{gl}^{-1}$ at the Causeway stations on Day 527. The maximum value observed during this bloom was $855 \mu \mathrm{g}^{-1}$ at a mid-Lake sample from $3 \mathrm{~km}$ to the west of Causeway Station 4, collected on 12 June, 1997. This bloom, consisting of Anabaena spp. and Microcystis sp., was able to rise to the surface water layer when winds were calm and cloud cover was negligible. We conclude that these bloom samples (Days 527 and 534) were not representative of an integrated water column sample and that the phytoplankton had collected in the surface layer. Although Anabaena spp. are capable of nitrogen fixation (Microcystis sp. does not fix N), very few heterocysts were observed during the peak of the bloom, indicating that nitrogen fixation was at a relatively low level (Turner et al. 2003a).

The ln transformed data for various nitrogen forms are shown in Figure 5. The samples collected on Days 527 and 534 were excluded because of the anomalous effects of the bloom described previously. The loss rate for nitrate was $5.12 \% \mathrm{~d}^{-1}$, compared to $1.75 \% \mathrm{~d}^{-1}$ for total nitrogen. Comparable slopes for dissolved inorganic nitrogen and organic nitrogen were -3.85 and -0.94 , respectively. These different slopes indicate that nitrogen transformations among various nitrogen forms were occurring within the Lake. Conservative mixing of the sum of these nitrogen forms is demonstrated (no net loss or gain of total nitrogen) because the slopes $\left( \pm 1\right.$ S.E.) for total nitrogen and - salinity were equal $\left(-1.75 \pm 0.35 \% \mathrm{~d}^{-1}\right.$ and $-1.78 \pm 0.07 \% \mathrm{~d}^{-1}$, respectively; Table 1$)$.

The apparent loss rate for silicate $\left(0.80 \% \mathrm{~d}^{-1}\right)$ was less than the rise for - salinity $\left(1.78 \% \mathrm{~d}^{-1}\right)$, implying a storage of silicate that is re-mobilized. A plausible source 
for silicate is from the diatoms present in the water column, although their numbers were not of bloom proportions. Another source of dissolved silicate is from the diagenesis of freshwater diatoms brought into the Lake during the diversion. There was no statistically-significant slope for $\ln$ total phosphorus or dissolved inorganic phosphate versus day. The slope for TN/TP was indistinguishable from the mixing rate of - salinity. The slopes for DIN/DIP and Si/DIN were higher than for - salinity, which is a consequence of the higher loss rates of nitrate. In other words, the loss rates of nitrate were higher than that of DIP or Si.

\section{Estimation of transformation rates}

Using this graphical approach to measure transformation rates does not require that an end-member diluent concentration be specified, as long as the decline in concentration $\left(\% \mathrm{~d}^{-1}\right)$ is linear and statistically-significant. We estimated the loss term for the period immediately after the diversion stopped based on the interval length for only the period when the decline in ln (concentration) was linear, and did not include any part that appeared curvilinear. We used the $R^{2}$ value to quantify linearity. In other words, the linear portion of the curve (Days 474-598 in Figure 5) is where the influence of the watershed sources of TN are least influential on the TN concentration in the Lake, and where the most accurate estimate of TN turnover in the diverted water can be made (Figure 5; Julian Days 480-600). This loss term was $1.75 \% \mathrm{~d}^{-1}$ for TN. We avoided having to know the seawater end-member concentration by judiciously using only the data for when the declining concentration (ln transformed) is linear. Because the loss term for freshwater volume and TN concentration were the same, we concluded that mixing of $\mathrm{TN}$ with the seawater end-member is conservative. (Note: A strong storm went through the area in late August 1997 that 're-set' the Lake's water quality. Extrapolating beyond then is inappropriate).

The loss term for DIN in the Lake after the diversion stopped was, therefore, not significantly affected by the concentration of nitrate in watershed sources because: (1) the concentration of DIN in the diverted water was relatively much higher than in the relatively small volume of water from local rivers ( $>80 \mu \mathrm{M}$ compared to $15 \mu \mathrm{M})$ and (2) the concentration of DIN in the Lake after 180 days was of similar or lower concentration than in the local riverine sources. The decline in DIN in the Lake was estimated to be $4.12 \% \mathrm{~d}^{-1}$ for the first 120 days after the diversion ceased, or more than twice the decline in TN concentration. We conclude that the mixing of DIN in the Lake with the seawater end-member is demonstrably non-conservative because the loss term for freshwater volume and the DIN concentration in the Lake were not the same for the first 120 days after the diversion ended.

\section{Discussion}

Nutrients in the Mississippi River water remained unchanged as water passed through the floodway and into Lake Pontchartrain in spring 1997. This water 
became the dominant freshwater and nutrient source for the Lake for the next 3-4 months. The DIN concentration declined at a much faster rate than the concentration of TN. TN, but not DIN, appears to be mixed conservatively. Because TN is conservatively mixed, but DIN is not, the conversion from DIN to ON is the explanation for why the decline in ON is about one-half the decline in TN. In other words, DIN is converted to $\mathrm{ON}$ at a rate equivalent to its loss from the Lake through conservative mixing. The diverted river water gradually mixed with coastal waters and was diluted to background levels at about $1.78 \% \mathrm{~d}^{-1}$. This is supported by two strong observations about the physical regime: (1) the concentration of total nitrogen in the Lake declined in proportion to the increases in salinity, a conservative tracer, and (2) the apparent dilution rate matched previously-published estimates of average freshwater turnover rates.

The zero nitrogen retention rate was much lower than that expected from a comparison of mass balances in some other studies. The nitrogen budget for 16 Danish lakes of similar $\mathrm{Chl}$ a, $\mathrm{TN}$ and nitrate concentration and depth were examined by Windolf et al. (1996). These 16 lakes had an average annual $\mathrm{N}$ retention that ranged from 11 to $72 \%$, which was about equally a consequence of both sedimentation and denitrification. Nielsen et al. (1995) used several methods, including modeling, isotope and mass balances, to measure nitrogen retention in a Danish fjord. They estimated that the estuary of their study, which had a freshwater retention time of 1.513 days, retained less than $3 \%$ of the total nitrogen loading. The freshwater turnover in Lake Pontchartrain is normally 537 days if only riverine freshwater sources are included in the calculation, but 56 days if tidal flushing is included (Swenson 1980a,b). If we accept this lower turnover time, then the estimated nitrogen retention rate is still much lower than one would expect based only on the graphs of nitrogen retention and residence time that Nixon et al. (1996) prepared. Trimmer et al. (1998) reported that the upper Great Ouse estuary had a freshwater flushing time of 3 days and retained $2 \%$ of the total oxidized nitrogen (nitrate + nitrite; TO $\times \mathrm{N}$ ). Comparable numbers for the lower Great Ouse estuary were a 25 days flushing rate and $56 \%$ $\mathrm{TO} \times \mathrm{N}$ retention rate. Their lower retention rate estimate was for an area with very little intertidal mudflats, and the higher retention rate was from an area that included the extensive intertidal mudflats of the Wash.

The higher rates of nitrogen retention for other estuaries of comparable size and flushing rates may be the result of confusion over whether or not the tidal flushing component of estuarine mixing coefficients represents all mixing terms, especially the tidal component. Also, some of the results of these previous studies did not include organic nitrogen when the nitrogen turnover budgets were constructed. This omission, in particular, may have affected the interpretation of the results, as Collos (1992) has warned. The conversion of inorganic to organic nitrogen in the overall estuarine nitrogen budget for Lake Pontchartrain appears to be significant. We estimate that the net gain of organic nitrogen from inorganic nitrogen increased the organic nitrogen pool by $0.83 \% \mathrm{~d}^{-1}$ (the difference in apparent loss rate for $\mathrm{ON}$ and the gain in salinity). The longer the flushing time, the more significance this conversion becomes when determining nitrogen retention. For example, Figure 6 includes a comparison of the consequences of different transfer coefficients for the 


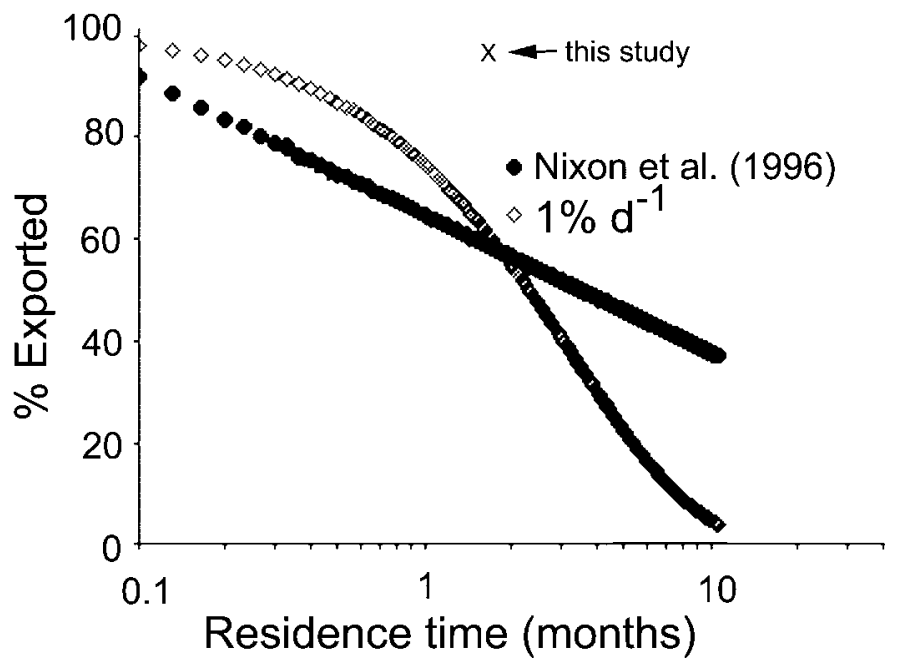

Figure 6. The relationship between estuarine residence time and the percent nitrogen exported from the estuary to offshore waters. The filled circle is the linear fit of literature data compiled by Nixon et al. (1996). The open diamond line is for a hypothetical $1 \% \mathrm{~d}^{-1}$ transfer turnover of nitrate to organic nitrogen. The results from this study are marked with an ' $\mathrm{X}$ '.

rate of nitrate to organic nitrogen conversion, including Nixon et al.'s analysis (1996). A net transfer rate as low as $1 \% \mathrm{~d}^{-1}$ of nitrate to organic nitrogen could easily, but mistakenly, be attributed to denitrification or sedimentation if the experimental error terms were high, or if all forms of dissolved nitrogen were not measured. Models might be compromised without the correct information on the nitrate-to-organic nitrogen transfer. The loss of dissolved nitrate above that from mixing was a non-trivial $3.34 \% \mathrm{~d}^{-1}$ in this example, and was not due to denitrification or sedimentation, but to conversion to organic nitrogen.

Nitrogen fixation in the Lake was estimated to be a trivial source of nitrogen relative to that brought in by the diversion (Turner et al. 2003a). The approaches described herein do not require direct measurement of net denitrification rates in order to estimate the net losses of nitrogen from the Lake. All changes in the size of the total nitrogen pool could be accounted for by tidal mixing. The apparent absence of significant net denitrification rates in Lake Pontchartrain may be due to the small area of intertidal mudflats and fringing vegetation, and also because the water column does not have the anaerobic conditions necessary for denitrification. In sum, neither $\mathrm{N}$ fixation or denitrification appears to be a significant factor affecting the nitrogen balance in the Lake during the four months after the diversion ceased.

\section{Acknowledgements}

The Lake Pontchartrain Basin Foundation and the guidance of staff members Messrs. N.A. Armingeon, C. Dufrechou, S. Gorin, and the Contract Officer, J. 
Waters, supported this work. Messrs. J.M. Lee, C. Milan, T.A. Oswald, and E.M. Swenson collected all water samples, which were analyzed in the Coastal Ecology Institute laboratories at Louisiana State University. Two unidentified referees and Dr. D. Justic' are thanked for their comments on various drafts of the manuscript.

\section{References}

APHA 1992. Standard Methods for the Examination of Water and Wastewater, 18th edn. American Public Health Association, New York.

Arar E.J. and Collins G.B. 1992. Method 445.0 In vitro Determination of Chlorophyll-a in Marine and Freshwater Phytoplankton by Fluorescence.Environmental Monitoring Systems Laboratory, Office of Research and Development, U.S. Environmental Protection Agency, Cincinnati, OH. Reprinted by Turner Designs, Sunnyvale, CA 94086.

Chuang W.-S. and Swenson E.M. 1981. Subtidal water variations in Lake Pontchartrain, Louisiana. J. Geophy. Res. 86: 4198-420.

Collos Y. 1992. Nitrogen budgets and dissolved organic matter cycling. Mar. Ecol. Progr. Ser. 90: 201-206.

Nielsen K., Nielsen L.P. and Rasmussen P. 1995. Estuarine nitrogen retention independently estimated by the denitrification and mass balance methods: a study of Norsminde Fjord, Denmark. Mar. Ecol. Progr. Ser. 119: 275-283.

Nixon S.W., Ammerman J.W., Atkinson L.P., Berounsky V.M., Billen G., Boicourt W.C., Boynton W.R., Church T.M., DiToro D.M., Elmgren R., Garber J.H., Giblin A.E., Jahnke R.A., Owens N.J.P., Pilson M.E.Q. and Seitzinger S.P. 1996. The fate of nitrogen and phosphorus at the land-sea margin of the North Atlantic Ocean. Biogeochemistry 35: 141-180.

Seitzinger G. 1988. Denitrification in freshwater and coastal marine ecosystems: ecological and geochemical significance. Limnol. Oceanogr. 33: 702-724.

Swenson E.M. 1980a. General hydrography of Lake Pontchartrain, Louisiana. In: Stone J.H. (ed) Environmental analysis of Lake Pontchartrain, Louisiana, its Surrounding Wetlands, and Selected Land Uses.Coastal Ecology Institute, Center for Wetland Resources, Louisiana State University, Baton Rouge, LA. Prepared for U.S. Army Corps of Engineers, New Orleans District, Contract No. DACW29-77-C-02523. pp. 57-155.

Swenson E.M. 1980b. General hydrography of tidal passes of Lake Pontchartrain, Louisiana. In: Stone J.H. (ed) Environmental analysis of Lake Pontchartrain, Louisiana, its Surrounding Wetlands, and Selected Land Uses.Coastal Ecology Institute, Center for Wetland Resources, Louisiana State University, Baton Rouge, LA. Prepared for U.S. Army Corps of Engineers, New Orleans District, Contract No. DACW29-77-C-02523, pp. 157-217.

Swenson E.M. 1981. Physical effects of the 1979 opening of the Bonnet Carré Spillway. Proc. Louisiana Acad. Sci. 44: 121-131.

Trimmer M., Nedwell D.B., Sivyer D.B. and Malcolm S.J. 1998. Nitrogen fluxes through the lower estuary of the river Great Ouse, England: the role of bottom sediments. Mar. Ecol. Progr. Ser. 163: 109-124.

Turner R.E. 2003. Nitrogen and phosphorus concentration and retention in water flowing over freshwater wetlands. In: Fredrickson L.H., King S.L. and Kaminiski R.M. (eds) Ecology and Management of Bottomland Hardwood Systems: The State of Our Understanding. University of Missouri-Columbia, Gaylord Memorial Laboratory Puxico, Mo. pp. 145-154.

Turner R.E. and Rabalais N.N. 1991. Changes in the Mississippi River this century: implications for coastal food webs. BioScience 41: 140-147.

Turner R.E., Dortch Q., Justic' D. and Swenson E.M. 2003a. Nitrogen loading into an urban estuary: Lake Pontchartrain. Hydrobiologia 487: 137-152.

Turner R.E., Rabalais N.N., Justic' D. and Dortch Q. 2003b. Global patterns of dissolved silicate and nitrogen in large rivers. Biogeochemistry 64: 297-317.

Windolf J., Jeppesen E., Jensen J.P. and Kristensen P. 1996. Modelling of seasonal variation in nitrogen retention and in-lake concentration: a four-year mass balance study in 16 shallow Danish lakes. Biogeochemistry 33: 25-44. 